\title{
2020 Transatlantic Security Jam: Resilience Going Forward
}

\section{Dinos Kerigan-Kyrou}

Cybersecurity Coordinator on the Joint Command \& Staff Course, Military College, Irish Defence Forces, https://www.military.ie/en/who-we-are/army/defence-forcestraining-centre/the-military-college/

\begin{abstract}
The 2020 Transatlantic Security Jam brought together military professionals and experts from a wide range of related disciplines. Their goal was to discuss and to analyze how NATO and its partners, including the European Union, can develop and enhance capabilities to address new and emerging security challenges. The online Security Jam took place soon after the start of one of the greatest asymmetric challenges we have seen - the COVID-19 pandemic. The pandemic has challenged every assumption on what is meant by security and resilience that we have had since the end of the Second World War. With this in mind, the participants proposed how we can both adapt to and proactively foresee emerging security challenges now and in the future. This article summarizes the discussions which took place and the proposals put forward. These proposals include a much more holistic approach to addressing security challenges that transcend the traditional 'siloed' or 'compartmentalized' approach we have grown so accustomed to.
\end{abstract}

Keywords: NATO, EU, asymmetric, emerging security challenges, security jam.

The May 2020 Security Jam focused on non-traditional challenges. Interestingly, the innovative solutions are also non-traditional. One of the clearest messages to arise from the Jam was the need to develop systems, processes, and institutions to predict and prepare for future challenges. In other words, to move beyond seeing problems in silos and hierarchical sectors and seeing a broader, holistic picture. (Indeed, this is something addressed directly 17 years ago in Chapter 13 of the $9 / 11$ Commission Report). This is especially true, as it was strongly 
argued through the discussions when these challenges are unpredictable or unknown; the famous "Unknown Unknowns." Throughout the debates in the six topic areas, there was an emphasis on sharing information, planning, and assisting one another -in both NATO and the European Union (EU) - to help prevent security challenges from occurring and minimize their impact when they do occur. The notion of unusual or asymmetric/ hybrid challenges was particularly emphasized, and it was felt that these types of challenges would be the greatest test to both NATO and the EU over the coming years. One of the key questions we can draw from the discussions is how this helps us in NATO-and the EUanticipate new challenges? In particular, how does this help in developing resilience?

A theme running through all of the discussions was the ability to share information in order to be able to 'see' new security challenges that are on-or even over - the horizon. These challenges will be asymmetric in nature - pandemics such as COVID-19 but also new pandemics that we do not yet know of; environmental challenges including climate change and poor air quality leading to public health issues; terrorism in changing forms; nefarious actors and states acting outside norms in cyberspace, misinformation and fake news, research and development and intellectual property theft, and human rights across the world. All of these are asymmetric or 'unusual' challenges that we perhaps do not yet have the ability to address with 'traditional' political and military structures designed for the Cold War. To increase resilience, what are the possible 'non-traditional' solutions for non-traditional challenges?

\section{Role of Technology}

In 2018 US House Representative Will Hurd highlighted the fact that people working in the financial sector will often have a better understanding of statesponsored cybercrime than the government intelligence services themselves. ${ }^{1}$ Rep Hurd argued that there needs to be not only better information sharing between private and public sectors to counter new threats, but the whole belief that it is government that understands threats and challenges better than business is perhaps an outdated assumption. As was made very apparent in the Jam - when we are dealing with new, asymmetric challenges that blur the lines between military and non-military threats, these old beliefs that "government knows more" may no longer be valid. There was strong backing for much closer collaboration between companies specializing in technology on the one hand and government on the other. Connected to this, another traditional assumption was challenged: The idea that a government-or an organization such as NATO or the EU-has a full, comprehensive understanding of a security problem before they issue a tender to industry. It was strongly suggested in the Jam that governments and international organizations may not fully understand the security

12018 Aspen Cyber Summit. Available at https://www.aspeninstitute.org/events/2018aspen-cyber-summit/. 
problem tthey wish industry to solve. Therefore, there should be far closer collaboration with the technology companies to enable them to help define the problem in the first place and indeed provide possible solutions. In short, assumptions about who understands a problem or a security challenge that has stood for decades need to be reassessed to create the most resilient environment.

Artificial Intelligence (AI) was seen as central to the collaboration with the tech companies. However, it was made clear in the Jam that Al is only as good as the initial information that is entered into the program. There is no substitute for accurate and clear "on-the-ground" data to feed into these Al models. Several examples were given where Al has been highly ineffective and even dangerous when the wrong information had been entered into the Al. While Al is crucial, it is only as good as the information proved by people - there is no substitute for on-the-ground intelligence to develop resilience.

While there was a strong call for much more integrated EU-NATO collaboration in the defense sector, there was also a recognition of the importance of the non-defense tech companies, such as Facebook, Google, Apple, and Amazon. In particular, the fact that the traditional security companies may no longer have a monopoly of the knowledge required for security - especially in the areas of emerging security challenges that sit outside "traditional" military boundaries. Because of this, NATO and especially the EU (which has strong regulatory powers), may need to change their relationship with these companies from "poacher/gamekeeper" to a much more collaborative relationship, it was argued. This may well enable huge development in addressing security challenges. It would also help address new and emerging challenges by using Al and, eventually, quantum computing. This is especially important if European economies are to successfully challenge the Chinese tech companies such as Tencent, Alibaba, and Huawei.

\section{EU and NATO - Creating New Structures to Work Together}

While the European countries (including the UK) spend more than Russia and China combined on defense, Europe at present has major challenges acting as a single defense actor. This is because of multiple duplications of defense programs across Europe and a lack of a single strategic and procurement strategy, thereby reducing resilience and the ability to plan and to predict future security challenges. Because of this, the Jam proposed the idea of a "Military Schengen Zone" that facilitates the movement of personnel and goods across Europe, reducing procedural obstacles, building on the success of the European Defence Agency and the gradual EU military integration occurring under Permanent Structured Cooperation (EU PESCO).

It was argued that significantly more integrated NATO-EU cooperation is needed to address emerging security challenges. Indeed, it was suggested by one participant that the initial "slow reaction to COVID-19" (before the response improved significantly) "highlights several deficiencies of both the EU and NATO." 
All the discussants agreed that international cooperation and international society post-COVID-19 should be based around several core principals, including:

- Pooling resources and expertise;

- Restructuring of power and leadership;

- Developing a flexible framework for EU and NATO decision-makers to make decisions to streamline and fast-track decision making;

- Improved coordination and sharing of information between NATO and the EU - including developing early warning mechanisms and avoiding EU / NATO duplication;

- Empowering citizens and the whole population to have much better situational awareness of emerging security challenges;

- Developing a "whole of society" approach;

- Better horizon scanning and enhancing resilience capabilities;

- Creating a better understanding of resilience, including aspects such as health and public trust;

- Investing in defense but realizing that security challenges are both military and "non-military";

- Working together to provide an alternative narrative to disinformation and misinformation.

Both NATO and the EU have their own emergency resilience coordination centers - EADRCC ${ }^{2}$ (Euro-Atlantic Disaster Response Coordination Centre) and ERCC $^{3}$ (Emergency Response Coordination Centre). It was felt that while both organizations have done outstanding work, especially during COVID-19, there is much more potential for these organizations. The discussants argued that member states of NATO and the EU could be utilizing these two bodies far more effectively than they presently do. Ideas were put forward regarding how the request to these organizations for action could be greatly streamlined. An idea put forward was that first responders and regional officials may be able to request EADRCC or ERCC action, rather than having to request assistance via central government channels, which can take several days when a rapid emergency response is desperately required. In summary, it was strongly argued that NATO's EADRCC and the EU's ERCC do exceptional work, but the broad understanding of these organizations and especially the local ability to directly request assistance in an emergency needs to develop and streamline very soon.

2 NATO EADRCC, https://www.nato.int/cps/en/natohq/topics_117757.htm.

3 EU ERCC, https://ec.europa.eu/echo/what/civil-protection/emergency-responsecoordination-centre-ercc_en. 


\section{New European, Transatlantic, and Global Institutions to Address New Challenges}

The role of institutions - both existing and potential-was highlighted considerably in the Jam. Of course, NATO and the EU were the focus of this analysis as two of the primary institutions in global affairs. Also of particular note was the Hybrid Centre of Excellence in Helsinki. Interestingly, Hybrid $\mathrm{COE}^{4}$ not only addresses hybrid resilience challenges but is itself a hybrid institution. Any EU or NATO state can become a member but, it is not actually a NATO or EU institution - it operates in a "third sphere," outside the direct control of NATO or the EU, enabling forward-looking and dynamic decision-making. The Jam considered hybrid COE to be crucial for the resilience of the EU and NATO.

The Jam also proposed new institutions to help address evolving security challenges faced by the EU and NATO, and to increase resilience. Perhaps the most ambitious proposal was a "Marshall Plan 2.0." This would focus on investment in new sectors and new infrastructure. A key part of this would be investing strongly in research and development, with particular support to small and medium-sized companies. Also proposed was a World Pandemic Security Organization to ensure effective coordination, communication, harmonization, planning, and inclusive cooperation among countries and regional alliances.

Other proposals to increase resilience included:

- A "NATO-Pacific Forum," to include the NATO Alliance plus Australia, Japan, New Zealand, and South Korea, and Columbia to address the challenges from China;

- NATO-EU Cooperation Center of Excellence, based on the current NATO COEs, but focusing on how NATO and EU cooperation can be developed and enhanced;

- Combating Fake News and Misinformation: a Strategic Communications Task Force dedicated to countering attacks on EU public opinion;

- NATO Hub for the South at Joint Force Command, Naples, working closely with EU EUROPOL (law enforcement) and FRONTEX (EU border control), and other multinational centers to build a counter-hybrid network.

\section{New Solutions for Resilience May Transcend the Historic "Nation State" Approach}

The Jam may have also produced some unexpected results.

During COVID-19, many have proposed the re-emergence of the nation state as the ultimate arbiter of international policy. There is a perception that in the Nationalism vs. Globalism debate, it is Nationalism that has come out on top recently. However, the Jam placed huge emphasis and indeed trust in organiza-

4 Hybrid COE, https://www.hybridcoe.fi. 
tions that are not nation-state-based, such as the European Centre of Excellence for Countering Hybrid Threats (Hybrid COE). There was also a determination to create new institutional structures to address new and emerging security challenges. In other words, while the Jam proposed that it is the inadequacies of the State structure which may have prevented a more resilient and effective approach.

\section{Unresolved Resilience Issues}

Perhaps the clearest 'unresolved' issue is: How exactly will the proposed ideas be executed? What is their practicality? The challenge might be summed up as, "Is what looks good on paper so good in practice?"

What is the timetable for these proposals to happen? How will they be budgeted and financed? Will individual countries need to borrow money-or will institutions such as the EU-or even NATO be given the authority to borrow and finance initiatives? How will the newly proposed institutions be comprised? Will they act on unanimity (like NATO)? Will they act on a combination of unanimity and majority voting (like the EU)? What will be their legal structures - will they be semi-autonomous from the countries, like the EU? Or will they be a straightforward reflection of their countries' positions, like NATO? Indeed, one of the most interesting unresolved questions is: should these new institutions be composed of nation-states at all, and if they are not composed of nation-states, what should they be consist of? The EU is an example of an organization that consists of Member States (the Council), direct democracy of EU citizens (the European Parliament), an executive (the Commission), and a judiciary (the European Court of Justice). Should the new institutions proposed be reflective of this system? Or should they be like NATO, which consists only of Member States? Should they have a powerful executive (like the EU Commission)? What of the democratic accountability of these proposed institutions? In sum, the Jam superbly addressed:

- What resilience problems are and why they matter?

- What the possible resilience solutions are?

But the questions that remain are:

- How will these resilience solutions happen?

- When will they happen?

- Where will they happen?

\section{Comprehensive Research Required into Feasibility of Proposed Resilience Ideas}

These unanswered questions lead us to what further research is required. More research is needed to: 
- $\quad$ analyze the proposals made. This is important if NATO and the EU are to justify the resources and, indeed, the time to pursue these ideas. It is crucial that this research is objective and impartial in order to reach the best possible analysis;

- $\quad$ understand how the proposals can be taken forward.

Topics that should be analyzed include:

- Human development gains, including broader societal gains arising from our ability to anticipate security challenges early and deal with these challenges in an effective way;

- Financial costs and financial gains;

- Risks-especially the "unintended consequences" - of taking forward proposals made during the Jam;

- Public "buy-in" to the ideas. In recent years, governments have been accused-rightly or wrongly-of taking forward ideas without consulting their populations and understanding their concerns. Research is required to ascertain whether these ideas proposed in the Jam address public concerns. What consultation can there be with societal groups to further develop these ideas? Indeed, it was specifically proposed in the Jam that empowering citizens and the whole population to have much better situational awareness of security is a key to developing our security. More research is needed into exactly how we do this. Modern Al and computer simulations can indeed enormously help in this task, but they are not a substitute for close and integrated public and stakeholder consultation - including consultation with the military;

- What is the role of current institutions such as Hybrid COE (NATO / EU), EADRCC (NATO), and ERCC (EU)? Before investing time and resources into developing new proposed institutions to improve resilience, there is an argument that we might investigate the further expansion-and possible further autonomy-of structures that already exist. One of the proposals put forward in the Jam was the application of Nordic-style ${ }^{5}$ civil preparedness/resilience and could be a model for the EU and NATO. How could such a "Nordic approach" be reflected across Europe and North America? Would such an approach invalidate the need to form new institutions? In other words - can we work with what "we already have"? Or do we need to create new institutions?

5 See, for example, Christer Pursiainen, "Critical infrastructure resilience: A Nordic model in the making?" International Journal of Disaster Risk Reduction 27 (March 2018): 632-641. Also see: Alberto Giacometti and Jukka Teräs, Regional Economic and Social Resilience: An Exploratory In-Depth Study in the Nordic Countries (Stockholm: Nordregio, 2019), https://doi.org/10.30689/R2019:2.1403-2503. 
The Jam identified new security problems - not only arising from COVID-19 but the potential for such "unknown unknowns" to occur again and again in future years. It proposed clear solutions to improve resilience, although more research is required to ascertain how these solutions can be put into practice. The role of the military in this new environment-where clear boundaries no longer exist-is incredibly unclear. New threats and challenges transcend the boundaries between military and non-military challenges, and yet we are, on the whole, operating in old structures within a new environment where these old assumptions are breaking down rapidly.

The role of objective strategic analysis and advising has perhaps never been more important; organizations such as the Partnership for Peace Consortium (PfPC) have worked closely with military academies and national governments across all NATO and Partner nations and almost all EU countries for over two decades. The PfPC has identified key aspects for change, and it is this type of analysis that is so crucial if we are to address these new asymmetric threats and challenges and become resilient. COVID-19 was not the first emerging security challenge we have faced, and it certainly will not be the last. In-depth strategic analysis-based on the invaluable findings of Security Jam 2020-is crucial for the resilience challenges we now face.

\section{Disclaimer}

The views expressed are solely those of the author and do not represent official views of the PfP Consortium of Defense Academies and Security Studies Institutes, participating organizations, or the Consortium's editors.

\section{Acknowledgment}

Connections: The Quarterly Journal, Vol. 19, 2020 is supported by the United States government.

\section{About the Author}

Dinos Kerigan-Kyrou, PhD, is the visiting lecturer in Strategic Cybersecurity at Abertay University Scotland. He is an instructor on the NATO DEEP (Defence Education Enhancement Programme) and is responsible for the cybersecurity training within the Joint Command \& Staff Course at the Irish Defence Forces. The author is particularly grateful to Dr. Raphael F. Perl for invaluable guidance on the structure and analysis of this article.

Email: d.kerigan-kyrou@abertay.ac.uk 